\title{
The Data Analysis of Information and Man-Machine Interaction in the Unconscious Design
}

\author{
Lixian Luo \\ Hubei Institute of Fine Arts. Wuhan, China
}

\begin{abstract}
Unconscious design" (Without Thought) is also known as the "intuitive design", which is a design idea. Namely: "Turning the unconscious actions into visible". Unconscious design embodies the interaction experience between person and product, it is not only improved the design field, so as to change people's life in further.
\end{abstract}

KEYWORD: The unconscious design; Information; Man-machine Interaction.

\section{INTRODUCTION}

Do we think about this: When you eat a kind of food with different seasonings (Joseph, 2002), Will you have different taste? Even first production of pottery was because of without thought design? And so on. It reflects that Interactive experience between person and product in unconscious design. (Kenya Hara, 2006).

\section{CONCEPT OVERVIEW}

\subsection{The concept of the unconscious}

The unconscious is not peculiar concept of the psychology. (Nathan shedroff, 2002) In Freud's psychoanalytic theory, the human consciousness is divided into three layers: Conscious, subconscious, unconscious. Freud believed that the unconscious has a dynamic role, it actively influence. (Nigel B, 1991) The unconscious as a power base is one of the determinants of human behavior, Unconscious impulse always strive to be satisfied and rise to the field of consciousness.

The main situation of Unconscious:

(1) Do not aware of, such as to pay no heed and listen.

(2) Be aware but not connected to other consciousness fragments, which soon lost.

(3) The consciousness of individual situations is organized in a large fragment of consciousness without special shows its existence.

\subsection{Concept of unconscious design}

"Unconscious design" (Without Thought) is also known as the "intuitive design", which Is a design idea. Namely: "Turning the unconscious actions into visible", which is Proposed by Naoto Fukasawa, who is an Industrial Design Master of Japan. Or it can be said that the design of the unconscious.

\subsection{Origin of unconscious design}

The concept of the" unconscious design" was first proposed by Japan Industrial Design Master Naoto Fukasawa, As Japan industrial design leader, Naoto Fukasawa integrated into essence of Japanese traditional culture, and put it into design and practice, and created the idea of "unconscious design", in the absorption of base of western classic design theory, he put the unconscious behavior of people as a source of inspiration, Make people realize the functions of product in the unconscious behavior. By conscious design, realizing unconscious behavior, and giving people a meaning enjoyment. Naoto Fukasawa, pay attention to emotion and detail in life, to grasp the relationship between products itself and the product of the environment, and he put these elements into his design practice. He said that no design specification is a good design, with minimal visual language, to mobilize our most abundant emotion, let us use more freely, rather than being controlled by products. Finally, through the above way, he designed a series of "unconscious" design classics and made an outstanding contribution to the development of industrial design in Japan and the world.

The "unconscious" is not really of no consciousness to participate, we know what we need something, But also not aware of what you want. Naoto Fukasawa pay attention to something is what we neglected about all the details of life of the "unconscious". He use a simple truth to explain the ideolog- 
ical roots of his design for us; When texting, Most people will choose to walk along the road which is used for the blind, he cannot go wrong without eyes to see. That is to say, the yellow road, which is usually provided for the blind, also reflects the new value. While walking is not only a learning behavior when you are children, it is in a kind of value for your foot. So, when you texting ,following the blind road line, is a kind of finding the value of sequential behavior, And when the people, things and environment reach perfect balance, We say that it found an unconscious valuable behavior.

\section{BACKGROUND OF UNCONSCIOUS DESIGN}

The "unconscious design", it is pointed out the crux of design field currently, with the development of design, many designs are not for the reasonable needs, design is increasingly being seen as individual designers' work. Naoto Fukasawa and other designer, attention to details in design and user experience. From his works, we can see the design ideal which are tried to achieve by he and all Japanese designers, do the design which is most close to the need of people.

\section{THE DATA ANALYSIS OF INFORMATION AND MAN-MACHINE INTERACTION IN THE UNCONSCIOUS DESIGN}

\subsection{Information of Interactive experience design}

Interactive experience design is a very broad field. It can predict that using of product how to affect relationship between user and product, and understanding of the products about user. And explore dialogue between product, people, material, culture, and life. Unconscious design also embodies the interaction experience between person and product, unconscious design especially need to research that Interactive experience about people's psychology in the unconscious, when using or improving design of product.

The unconscious design is a great design field, and is not confined to the classroom, it is the research in life, it reflects the interaction experience between person and product, unconscious design of Naoto Fukasawa's study is the highest stage of unconscious design field. (Of course, unconscious design field is also reflected and used in the webpage, graphic design, clothing design and other aspects, but this paper focuses on the field of product design)

\subsection{The Data analysis of Psychological cognitive model}

For the using of the product, the user has a psychological model, simply, this is the style of user using product .The working principle and function of product is the implementation model, which is Presented by the performance model, but there is different between psychological model and implementation model. (Table 1)

Table1. Mental model

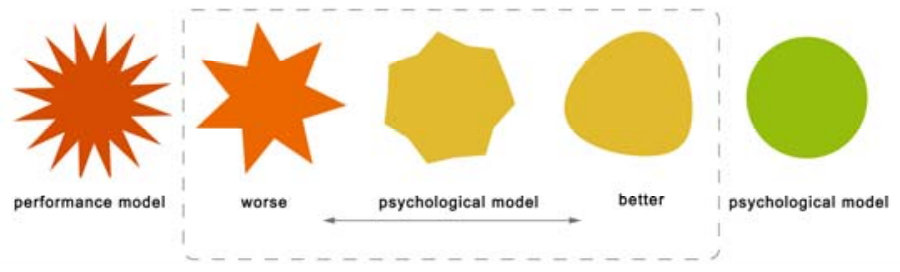

For example, consciousness of people for the time, we often find that, in some cases, the time seems shorter, in other cases, the time seems longer. As shown in Table 2, this is different consciousness of people in 1 minute for the time, this shows that there is some relationship between the state of unconsciousness of people and many factors. For example, different material texture also will affect people's unconsciousness. (Table3)

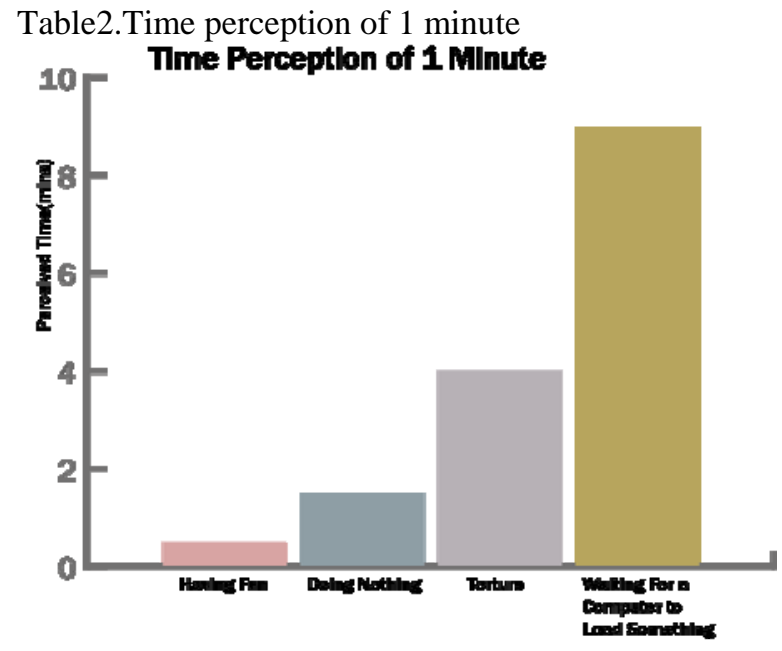

Table3. Perception of touch of materials characteristics

\begin{tabular}{|c|c|c|c|c|}
\hline material & $\begin{array}{l}\text { Degree of } \\
\text { harrness }\end{array}$ & $\begin{array}{l}\text { Degree of } \\
\text { hot and cold }\end{array}$ & retrievability & $\begin{array}{l}\text { Sensory } \\
\text { characteristics }\end{array}$ \\
\hline Wood & $4-7$ & $1-3$ & High & Mild \\
\hline Bamboo & $5-7$ & $3-5$ & High & light \\
\hline leather & $1-3$ & $1-3$ & High & Flexible \\
\hline Rubber & $3-4$ & $4-6$ & High & Rough \\
\hline Ceramic & $8-9$ & $7-8$ & High & thermostability \\
\hline Glass & $7-8$ & $5-6$ & High & Fragile \\
\hline
\end{tabular}

\subsection{Stage of unconscious design}

We can understand that unconscious design is the application research of human subconscious behav- 
ior, reflecting in the specific design, is a process of "unconscious (life experience) -- to consciousness (summary life experience) -- to the unconscious (design experience)". The unconscious design does not mean that the designers with the design at will. On the contrary, it is the "conscious" plan before understanding that experience involved in the process unconsciously. Also can say, beauty of the unconscious design is perfect psychological guidance unobserved.

Therefore, the unconscious design can be divided into the following three stages from elementary to advance.

\subsubsection{Unconscious}

Unconscious design is formed through unconscious state. For example, books are usually used to read, which stacked up also can become a temporary stool. (Fig. 1)

\subsubsection{Recycling}

Reusing product which is lost original using value, then playing a new value for it. For example, look at this lamp, even people use a waste glass bottle to do. (Fig. 2)

\subsubsection{Conscious}

Using people's unconscious to guide design, and then using conscious design to become unconscious state finally. For example, this is a desk lamp with a tray which designed by Japan Industrial Designer Naoto Fukasawa. Let us imagine a scene, When at the end of the work day, you return home and feel tired, you will put the key down and then turn on the desk lamp, The design of this lamp is skillfully grasp the details, he make the base of the desk lamp to be a plate shape, You can put the keys into the plate at will, then the light on automatically, And when you want to leave, taking the keys, at the same time, the light go out automatically, so the lamp becomes a finishing point at the end of the day and a starting point of new day. (Fig. 3)

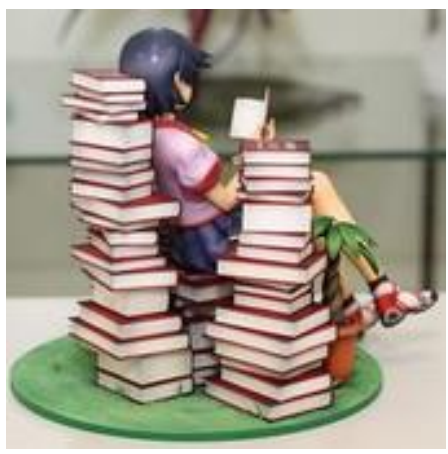

Fig. 1 Book

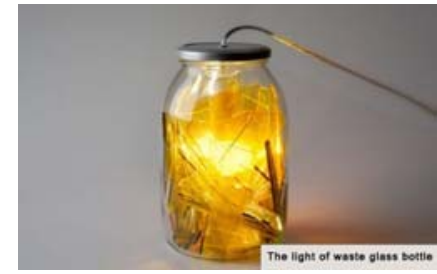

Fig. 2 Light

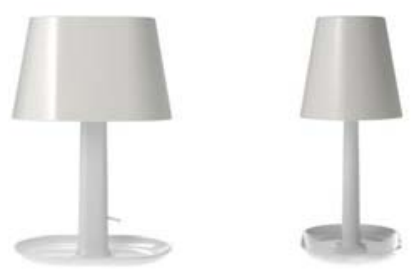

Fig. 3 Light

The presence of design is not to show off the design itself. Do not add trival function, but from human consciousness. But if someone think that unconscious design is no conscious, "anti planning" is no planning design, it is the opposite conclusion of original intention of the designers.

The author once participated in unconscious design issues which organized by German professors of Keele University, sometimes, people will change the fixed attribute and function of common goods, and excite its other functional property to meet the new demand of behavior. For example, a group of students went to research the kitchen of school canteen, They found that, due to the canteen cooker was huge, generally small spatula could not use, people replaced spatula with besom. But the besom is not supposed to sweep the floor? They also found that, some goods of kitchen of school canteen were excited their other functional properties. (Of course, the aforementioned besom, is specially used for cooking and washing the pot, impossible to sweep the floor, in order to protect the health requirements)

\section{CONCLUSION}

5.1 The unconscious is another form of in-depth research in product design. Not only through the shape, color, to design and change the product, but through the study of the users' psychology.

Especially in today's highly developed industrial design, Many designers use their thoughts to create a new way of life , thus increasing the people's "adaptation burden "."No conscious design" is not a new kind of design, but pay attention to details which are some others unaware of, and amplify these details. Into the original product. Sometimes this change is greater than creating a new product. 
5.2 The research of the unconscious design may lead to design changes, which affect the change of life style.

For example, before the pottery production, human ancestors and other animal, rely solely on their own organs and physical activity to survive. When they are thirsty, they put their mouth close to the water or holding the water to drink by hands. When they can't use their mouth close to the water, they must use the container to achieve the goal of drinking water. When they noted that shell, or puddle can have storage water, the concept of containers will become unconscious, and accumulated gradually and became the original "collective unconscious". So they relied on intuition to create and practice, using the water, soil and other materials, making pottery from copying. The processing behavior became the first human intuition design-The unconscious design. In This design, no matter how simple about the initial demand, no matter how simple about initial controller process, this creation is in order to adapt to the human survival. Undoubtedly, it is beyond intuition and understanding of nature container (shell, puddles).

Thus, the unconscious design is not only improved the design field, even It can produce design changes, It is not though a new dream, but may produce new things, so as to change people's life in further.

\section{REFERENCES}

Joseph, Experience economy, Gilmore, 2002, mechanical industry publishing

Kenya Hara, 2006, Design in the design, Shandong people publishing

Nathan shedroff, 2002, Experience Design 1, New Riders Publishing

Nigel B, 1991, what is Usability, 4th International Conference on HCI, 165-169 